\title{
Optimization of the Tracer Particle Addition Method for PIV Flowmeters
}

\author{
Yilong Qiu ${ }^{1, *}$, Huiyu Chen ${ }^{1}$, Wangxu $\mathrm{Li}^{2, *}$, Feng $\mathrm{Wu}^{2}$ and Zhenggui $\mathrm{Li}^{2}$ \\ 1 Natural Gas Research Institute, PetroChina Southwest Oil \& Gas Field Company, Chengdu 610213, China; \\ chhy@petrochina.com.cn \\ 2 School of Energy and Power Engineering, Xihua University, Chengdu 610039, China; \\ 212020080700013@stu.xhu.edu.cn (F.W.); lzhgui@mail.xhu.edu.cn (Z.L.) \\ * Correspondence: qiuyilong@petrochina.com.cn (Y.Q.); 212019080700005@stu.xhu.edu.cn (W.L.)
}

check for updates

Citation: Qiu, Y.; Chen, H.; Li, W.; $\mathrm{Wu}, \mathrm{F}$; $\mathrm{Li}, \mathrm{Z}$. Optimization of the Tracer Particle Addition Method for PIV Flowmeters. Processes 2021, 9, 1614. https://doi.org/10.3390/ pr9091614

Academic Editor:

Krzysztof Rogowski

Received: 5 August 2021

Accepted: 7 September 2021

Published: 8 September 2021

Publisher's Note: MDPI stays neutral with regard to jurisdictional claims in published maps and institutional affiliations.

Copyright: (c) 2021 by the authors. Licensee MDPI, Basel, Switzerland. This article is an open access article distributed under the terms and conditions of the Creative Commons Attribution (CC BY) license (https:/ / creativecommons.org/licenses/by/ $4.0 /)$.

\begin{abstract}
When a PIV flowmeter is used to measure a large flow of natural gas, the flow field fluctuation and particle distribution have a significant influence on the measurement accuracy and the particle injection mode plays a key role in the flow field fluctuation and particle distribution. To improve the measurement accuracy of PIV flowmeters, the method of filling tracer particles in single pipes, multiple pipes, and L pipes of a natural gas DN100 pipeline under high-pressure working conditions was compared and analyzed through numerical calculation and testing. The results show that the disturbance distance of filling particles in L pipes was the shortest, but the particle distribution area was small, whereas the flow metering error was large. By shortening the intersection distance between the $\mathrm{L}$ tube injection flow field and the main flow field, the problem that the particles failed to fill the test area was effectively solved, and the peak turbulence intensity at the intersection of the flow field decreased from $13.4 \%$ to $8 \%$. Furthermore, the optimized structure was used to measure a flow of $100-600 \mathrm{~m}^{3} / \mathrm{h}$ with different flow rates. The relative error between the flowmeter and the ultrasonic flowmeter was approximately $2 \%$, and the metering deviation was significantly improved.
\end{abstract}

Keywords: tracer particles; PIV; flowmeter; natural gas

\section{Introduction}

With the rapid development of the world's industry, the demand for energy in various countries is continuously increasing. As a high-quality and efficient primary energy source, natural gas has become the first choice for industrial energy consumption in various countries [1]. Natural gas is a type of gaseous hydrocarbon produced by microbial decomposition after long-term accumulation of paleontological remains in the ground. Therefore, the distribution of natural gas reserves in the world is related to geographical location [2]. Countries with developed industries but small natural gas reserves need to trade natural gas with countries with rich natural gas reserves [3]. Today, natural gas trade plays an important role in international trade, promoting global economic integration.

Fair trade is a key premise of international trade. In the international trade of natural gas, the accuracy of large flow measurement is particularly important not only for economic interests, but also to maintain the stable operation of the international trade of natural gas. At present, ultrasonic flowmeters are widely used in natural gas large flow measurement. Its measurement principle is to use the different propagation speeds of ultrasonic waves in different fluid flow velocities. The manufacturing cost has nothing to do with the diameter of the pipeline, especially in large diameter, large flow measurement, has the advantages of convenient installation and use. However, there is a high demand for measurements in noisy environments. If the pipeline scales or the measurement environment has noise, the measurement accuracy will be severely affected [4]. Therefore, in the international trade of 
natural gas, a new type of flowmeter with high precision and strong resistance to external interference is urgently needed.

With the development of computers and image processing technology, the particle image velocimetry (PIV) technique has become an important method to test the microscopic flow characteristics of flow fields [5,6]. Xiaolong et al. used PIV testing technology to analyze the internal flow field and pressure pulsation in the bladeless region of a pump turbine [7], Moneib et al. studied the near-field spray characterization of an overflow return atomizer using a PIV laser [8], Seon and Jin used PIV technology to study the effect of buoyancy on mixed convection in vertical channels [9], and Gangfu et al. used PIV technology to measure the velocity field in the rotating boundary layer [10]. The above studies were all based on PIV technology, and all achieved good results.

The principle of PIV testing is that the flow field at the transparent pipe is irradiated at a high frequency by a laser connected to a synchronizer and computer to capture tracer particles in the flow field, and the velocity information of the flow field is obtained by taking a series of displacement photos of particles in the flow field with a high frequency camera [11-13]. In this type of experiment, it is necessary to form a complete set of equipment placed around the transparent pipes, which can then be measured. This method possesses the advantages of convenient installation and simple operation because it is based on tracer particles of the pulsed laser refractive reaction flow field characteristics, making it less sensitive to outside interference; furthermore, the accuracy of PIV testing of the flow field has been thoroughly experimentally validated [14-16]. Therefore, the application of PIV technology in large flow metering of natural gas has the advantages of convenient installation and use, strong anti-noise ability and long service life.

The addition of tracer particles is a key step in PIV testing. At the intersection of the particle injection flow field and test flow field, a flow field disturbance will inevitably be generated, and under the action of shear force, the disturbance will gradually weaken and disappear along the flow direction. In a PIV flowmeter, the distance from the confluence of the flow field to the disappearance of the flow field disturbance is called the disturbance distance. If the PIV flowmeter is installed within the disturbance distance, it will cause a large metering error, so the disturbance distance must be taken into account in the application of PIV flow timing. The particle distribution outside the disturbance distance also affects the accuracy of the PIV flowmeter. Therefore, it is necessary to study the disturbance distance and particle distribution of PIV flowmeters.

In this paper, a large flow DN100 natural gas pipeline is taken as the research object, and the disturbance distance caused by different particle injection modes in the PIV flowmeter is analyzed through numerical calculation. The injection mode with the smallest disturbance distance is obtained, and the injection mode is optimized by combining numerical calculation and testing. The measurement results of a PIV flowmeter with an optimized structure were compared with those of an ultrasonic flowmeter to verify the feasibility of the PIV flowmeter with an optimized structure. This study provides a theoretical reference for the development of PIV flowmeters.

\section{Materials and Methods}

When using a PIV flowmeter, the injection fluid and the fluid in the main pipeline of natural gas flow in their respective pipelines, resulting in the generation of fluid collision and disturbance at the intersection. The entire process should follow the mass conservation and momentum conservation equations [17]:

$$
\begin{gathered}
\frac{\partial \rho}{\partial t}+\frac{\partial}{\partial x_{k}}\left(\rho u_{k}\right)=0 \\
\rho \frac{D u_{j}}{D t}=\frac{\partial \sigma_{i j}}{\partial x_{i}}+\rho f_{j}
\end{gathered}
$$


where $\rho$ is the fluid density, $\vec{\tau}_{i j}$ is the viscous shear stress of the fluid, and $\overrightarrow{\mathrm{F}}$ is the volumetric force on the fluid. Tracer particles are injected into the natural gas pipeline by the particle injector using differential pressure and are fully mixed with the natural gas. Owing to the action of gaseous natural gas, the virtual mass force, pressure gradient force, drag force, and buoyancy force should be taken into account in the movement of tracer particles in the flow field [18]:

$$
\begin{gathered}
m_{p} \frac{d \overrightarrow{u_{p}}}{d t}=\frac{C_{d} R_{e p}}{24 \tau_{t}}\left(\vec{u}-\overrightarrow{u_{p}}\right)+\frac{\vec{g}\left(\rho_{p}-\rho\right)}{\rho_{p}}+\left(\frac{\rho}{\rho_{p}}\right) \nabla P+C_{v m} \frac{\rho}{\rho_{p}}\left[\overrightarrow{u_{p}}\left(\vec{u}-\overrightarrow{u_{p}}\right)-\frac{d \vec{u}}{d t}\right] \\
\tau_{t}=\frac{\rho_{d} d_{p}^{2}}{18 \mu} \\
R_{e}=\frac{\rho d_{p}\left(\vec{u}-\overrightarrow{u_{p}}\right)}{u} \\
C_{d}=\frac{1}{R_{e p}^{2}}\left(a_{1} R_{e p}^{2}+a_{2} R_{e p}+a_{3}\right),
\end{gathered}
$$

where $m_{p}$ is the grain quality, $\frac{d \overrightarrow{u_{p}}}{d t}$ is the acceleration of a single particle, $C_{d}$ is the drag coefficient, $\vec{u}$ is the fluid velocity, $\overrightarrow{u_{p}}$ is the particle velocity, $\vec{g}$ is the gravitational acceleration, and $C_{v m}$ is the fictitious quality factor.

At the confluence of the flow fields, the fluid flow state is extremely unstable, and the turbulence intensity is an important parameter to characterize the microscopic pulsation characteristics of the flow field. The symbol $I$ is used to represent the intensity of turbulence:

$$
I=\frac{u \prime}{\bar{u}}=0.16(R e)^{-\frac{1}{8}}
$$

When exploring the flow characteristics of the flow field in the pipeline, turbulence intensity is an important standard. When the turbulence intensity is small, the flow field tends to be stable [19-21].

The above Equations (1)-(7) is integrated through the numerical simulation software FLUENT, and we use FLUENT to simulate the flow field of natural gas pipeline in this paper.

The principle of PIV flow measurement is that the laser emitted by a pulsed laser source is used to form a sheet light source in the measurement area through a sheet light lens. The tracer particles, which are fully mixed with natural gas, pass through the light area. The flow characteristics are captured by a CCD camera, the particle velocity vector is calculated by the built-in PIV algorithm, and the particle velocity is replaced by the flow field velocity.

In the measurement section of a DN100 natural gas pipeline, the axial change of the flow field velocity can be ignored because the axial distance is short and there is no flow stopper inside the pipeline. The radial distribution of the flow velocity is similar to that of circular straight pipe, which gradually decreases from the axial center along the radial direction. We take a certain axial section of the measuring section and calculate the flow rate through the section by method of the ring integral.

The principle of the loop integral is as follows: In the internal PIV algorithm DPIV, the calculation area (Line A) is automatically divided into equal distances, divided into several small areas, and defined as the query area. As shown in Figure 1. The average velocity of the tracer particles in the query area is used to replace the flow velocity of the query area. We define $V_{N}$ as the speed of query area $N, V_{N+1}$ as the speed of query area $N+1$, $R_{N}$ as the distance from query area $N$ to the center of the pipeline, and $R_{N+1}$ as the distance from query area $N+1$ to the center of the pipeline. Query area $N$ is adjacent to query area $\mathrm{N}+1$, and $\mathrm{R}_{\mathrm{N}+1}>\mathrm{R}_{\mathrm{N}}$. We define the area of a ring with an inner diameter $R_{N}$ and an outer 
diameter $R_{N+1}$ as $S_{N}$. The product of $S_{N}$ and $V_{N}$ is the flow rate through the annular region. The flow through each annular area is the sum of the flow through that section.

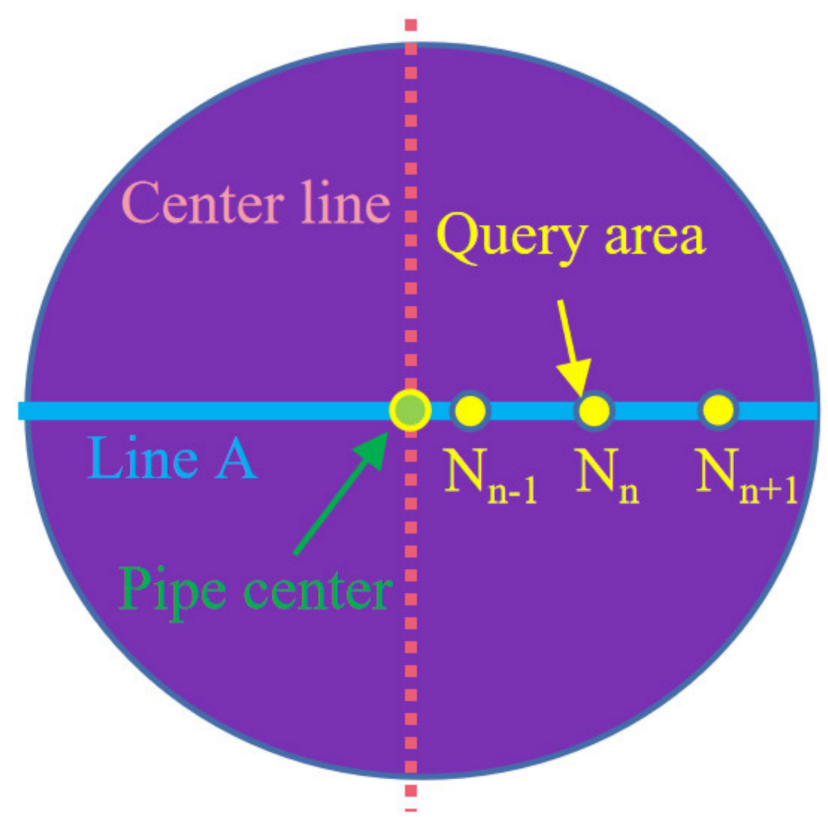

Figure 1. Loop integral diagram.

In order to explore the influence of particle injection modes on the disturbance distance, in this study, we perform numerical calculation regarding a single pipe injection, multi-pipe injection, and $\mathrm{L}$ pipe injection, and compare the disturbance distance. The model is shown in Figure 2. The diameter of the main pipe is $100 \mathrm{~mm}$, and the total length of the main pipe is $5000 \mathrm{~mm}$. The vertical intersection of the flow field causes backflow. In order to prevent the flow from flowing out of the control body under the action of backflow, ensure the full development of the main flow field, and increase the stability of the calculation, the filling pipe is placed $800 \mathrm{~mm}$ away from the inlet of the main pipe.

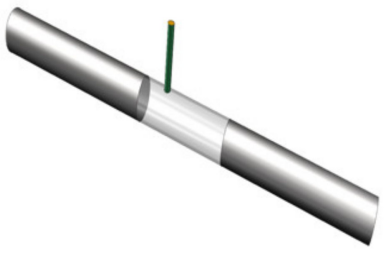

CASE1

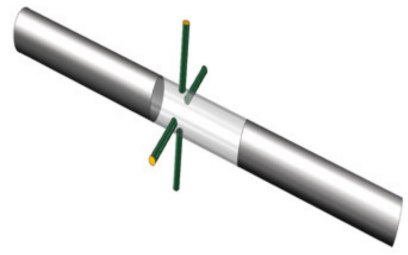

CASE2

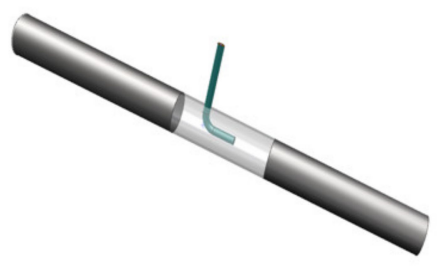

CASE3

Figure 2. Particle injection modes.

In the PIV flowmeter, when the diameter of the filling pipe is too large, the high pressure resistance of the pipe is affected; when the diameter is too small, the particles are blocked, resulting in particles that do not mix well with the natural gas fluid. Therefore, in this study, the diameter of the filling pipe is $6 \mathrm{~mm}$.

After being pressurized by the particle emitter, the tracer particles are transported to the vertical section of the filling pipe through a hose, then enter the main flow field and fully mix with the main flow field. If the vertical pipeline length is short, the flow pattern of the injection flow field cannot be fully developed; if the vertical pipeline length is long, it wastes processing materials and impairs the connection between the hose and the vertical pipeline. After the field investigation of the natural gas large flow measuring station, the optimal vertical length was determined to be $200 \mathrm{~mm}$. The horizontal pipe length (Lx) of the L-type filling is $80 \mathrm{~mm}$ (see Figure 3). 


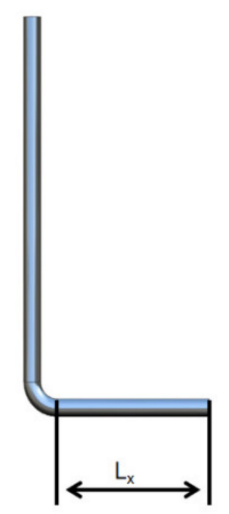

Figure 3. Schematic diagram of L pipe.

The grid model draws the structural grid using ICEM, and the grid independence test shows that when the grid number of the three schemes reaches $4,933,259$, the speed of the monitoring points changes only minimally with an increase in the grid number.

The numerical calculation is carried out with fluent 18.2, and the axial direction of the main pipe is $x$ direction. The inlet is set as a mass inlet, the fluid medium is methane, the density is the ideal gas density, the operating pressure is $2 \mathrm{MPa}$, the operating temperature is $20^{\circ} \mathrm{C}$, the difference between the injection pressure and the main pressure is $0.5 \mathrm{MPa}$, the particle model is a droplet model, the particle size is $10 \mu \mathrm{m}$, and the mass flow is $1 \times 10^{-20} \mathrm{~kg} / \mathrm{s}$. The particles are affected by the drag force, buoyancy force, pressure gradient force, and virtual mass force in the flow field. Since there is a large pressure gradient in the calculation, the realizable $\mathrm{K}-\varepsilon$ turbulence model have been used. The wall has a reflection effect on particles, and the reflection angle is $45^{\circ}$.

\section{Results}

\subsection{Disturbance of Flow Field Caused by Different Filling Methods}

Figure 4 shows the cloud diagram of turbulence intensity distribution in the main pipeline at a flow rate of $100 \mathrm{~m}^{3} / \mathrm{h}$ and an injection pressure of $2 \mathrm{MPa}$. When the turbulence intensity decreases to $3 \%$, it has little influence on the measurement results of the PIV flowmeter, and the disturbance caused by confluence is negligible. Therefore, at $100 \mathrm{~m}^{3} / \mathrm{h}$ and $2 \mathrm{MPa}$, the disturbance distance of the three schemes is four times the pipe diameter. Thus, there is no significant difference between the three schemes in terms of the downstream disturbance distance when the flow rate is small.

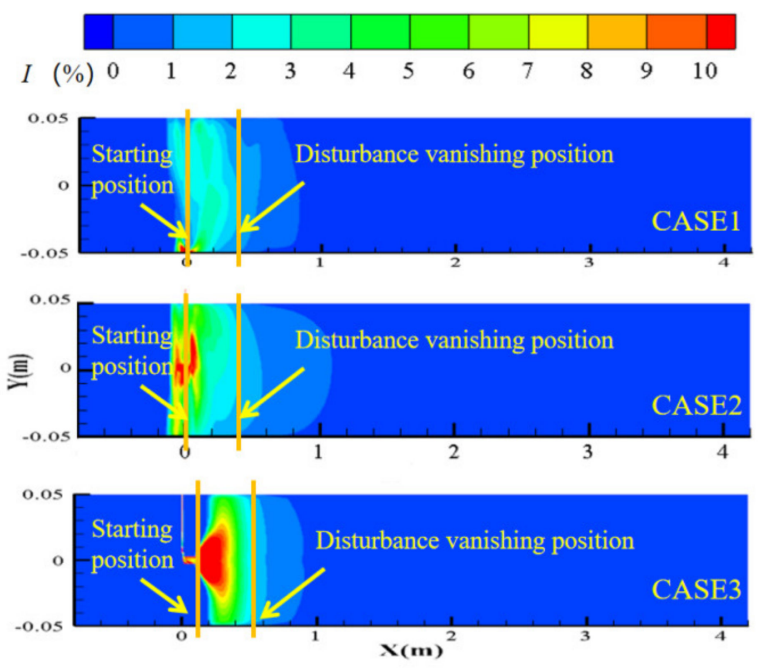

Figure 4. Turbulence intensity caused by different filling modes. 
Figure 5 shows a comparison of the disturbance distances of the three schemes under the same injection pressure and different flow rates. As shown in Figure 5, the disturbance distance of each scheme increases with an increase in the flow rate, among which CASE2 has the largest growth rate and CASE3 has the smallest growth rate. In addition, the disturbance distance of CASE3 tends to be stable after the flow rate of $400 \mathrm{~m}^{3} / \mathrm{h}$, and does not continue to increase with an increase in the flow rate. The main reason for this phenomenon is that the injection flow fields of CASE1 and CASE2 intersect vertically with the mainstream field, resulting in a large disturbance of the mainstream field. In addition, the injection flow field of CASE2 intersects with the mainstream field in four directions, so the disturbance distance of CASE2 is large. The filling flow field of CASE3 is in the same direction as the flow field of the main flow field, and the disturbance caused by the confluence of the flow fields is small. However, because the filling pipe of CASE3 needs to extend into the main pipe, it has a blocking effect on the main flow field. Therefore, the flow field disturbance in CASE3 mainly comes from fluid impinging on the filling pipe, and this disturbance also increases with an increase in the flow rate in the main flow field; however, the disturbance disappears quickly. Therefore, after CASE3 reaches $400 \mathrm{~m}^{3} / \mathrm{h}$, the disturbance distance of the flow field no longer increases. Of the three filling modes, CASE3 has the least impact on the mainstream field. Therefore, in this PIV flowmeter test, CASE3 is selected as the particle filling mode, and the installation position of the PIV flowmeter should be greater than eight times the pipe diameter.

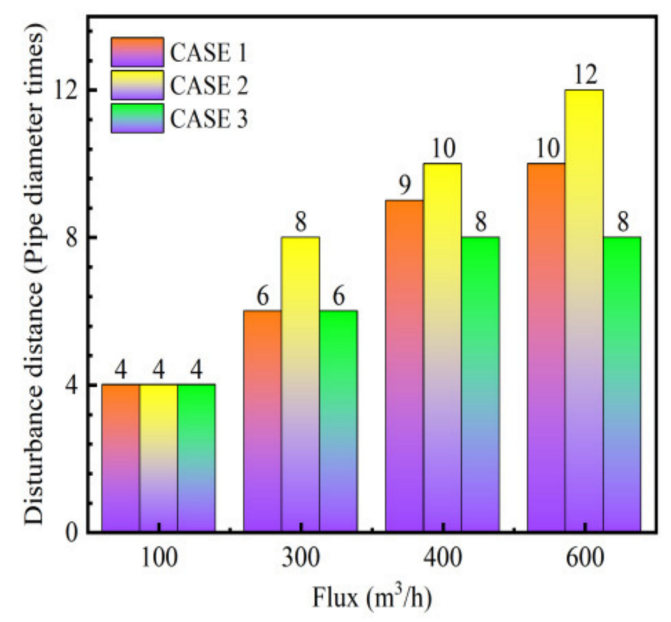

Figure 5. Relationship between disturbance distance and flow rate for different schemes.

\subsection{Analysis of Measurement Results of PIV Flowmeter with CASE3 Filling Mode}

The optimal position of the PIV flowmeter was obtained through numerical calculation when the CASE3 particle filling mode was applied. Considering that the disturbance distance would be adversely affected by unstable filling pressure in actual working conditions, the PIV device was installed at a pipe diameter 20 times from the intersection of the flow field. Figure 6 shows the particle charging device; the tracer particle test uses the droplets of particle size of $10 \mu \mathrm{m}$. In the initial stage, the particle injection pressure was set to 2.1-2.3 MPa. However, compared with the atmospheric pressure, the concentration of tracer particles captured by the CCD camera was significantly reduced in the high-pressure natural gas test. According to our analysis, this was caused by the increase in gas pressure and the speed of gas flow. As the gas velocity increases, the tracer particles can travel longer distances per unit time, which means that the concentration of the tracer particles becomes thinner in the fixed volume of the visible pipe. Therefore, to increase the concentration of tracer particles in the visible pipe, we adjusted the filling pressure to $2.5 \mathrm{MPa}$. Filling the device through the resistance to the high-pressure hose connected to the particle filling gas DN 100 pipeline. The gas flow rate is controlled by the upstream flow-limiting valve; in the test process, the natural gas flows are 99.81, 196.54, 300.18, 402.11, 501.35 and $598.66 \mathrm{~m}^{3} / \mathrm{h}$. 
The corresponding time intervals $(\Delta t)$ between two laser pulses of the PIV system are 100, $90,80,70$ and $60 \mu$ s, respectively.

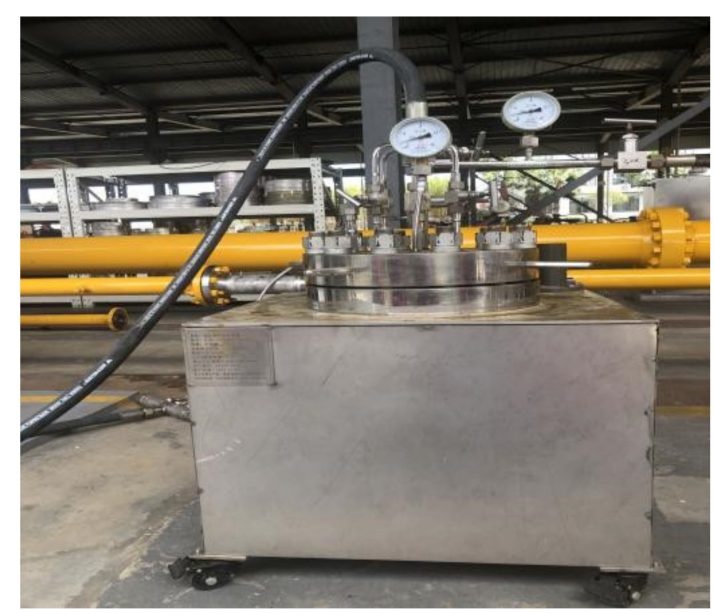

Figure 6. Particle charging device.

Figure 7 contrasts the PIV flowmeter measurement results with the ultrasonic flowmeter measurement results. The figure shows that in small flow conditions, the relative errors of the two kinds of flowmeter measurement results are small, indicating reliable measurement results. However, with an increase in the flow rate, the PIV flowmeter and ultrasonic flowmeter measurement results are significantly different; in the $600 \mathrm{~m}^{3} / \mathrm{h}$ case, the relative error value reached more than $6 \%$ (relative error value $=$ (ultrasonic measurement results_PIV measurement results)/ultrasonic measurement results).

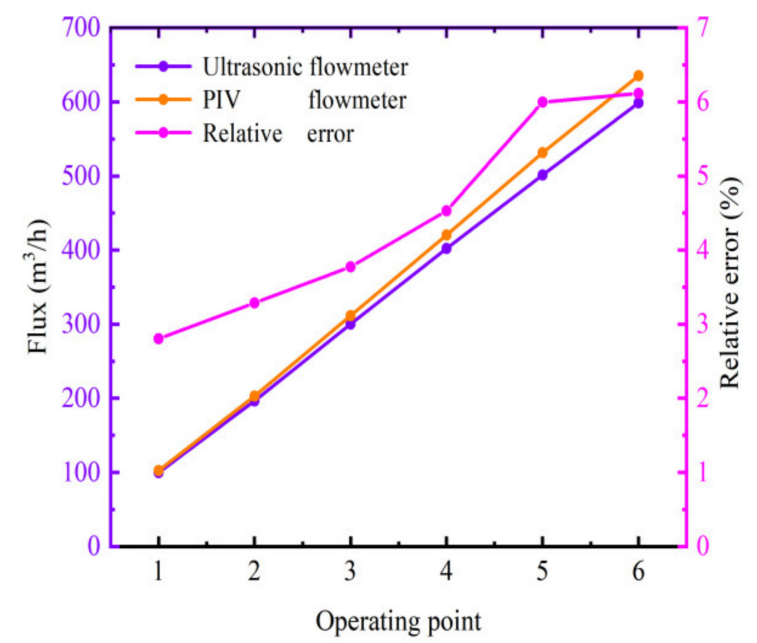

Figure 7. Measurement error.

Through the analysis of the particle vector map taken by a CCD camera, it is found that the tracer particles and main gas are not fully mixed under high flow rates, hence the particles do not fill the entire pipe. To improve the metering accuracy of PIV flowmeters, it is necessary to study the particle distribution law.

\subsection{Influence of Flow Rate on Particle Distribution}

Figure 8 shows the distribution of CASE3 tracer particles at different flow rates under the pressure difference of $0.5 \mathrm{MPa}$. As shown in Figure 8, when CASE3 is used to add tracer particles, the tracer particles are mainly concentrated in the center of the pipeline, which has a great impact on the measurement results of the PIV flowmeter. Tracer particles are mainly concentrated in the center of the pipeline, and with an increase in the flow rate, 
the particles tend to be close to the center of the pipeline, so the metering errors of the PIV flowmeter and ultrasonic flowmeter increase with an increase in the flow rate. At $100 \mathrm{~m}^{3} / \mathrm{h}$, the particle distribution area accounts for about $16 \%$ of the cross-sectional area of the pipeline. At $300 \mathrm{~m}^{3} / \mathrm{h}$, this value decreases to about $4 \%$ of the pipeline cross-sectional area; at $600 \mathrm{~m}^{3} / \mathrm{h}$, this value further decreases to approximately $1 \%$ of the cross-sectional area of the pipeline. As the flow rate of the main pipe increases, the fluid flow pattern fully develops and the flow field pulsation decreases, so the pulsation of the flow field itself cannot cause the particles to reach the area near the pipe wall, which explains this phenomenon. Thus, when tracer particles are injected into the $\mathrm{L}$ tube, the distribution area of particles is inversely proportional to the velocity; thus, reducing the velocity is one measure by which the distribution area of particles can be effectively increased. However, under certain conditions, large velocities cannot be avoided, so this method of reducing the velocity cannot be applied to all fields.

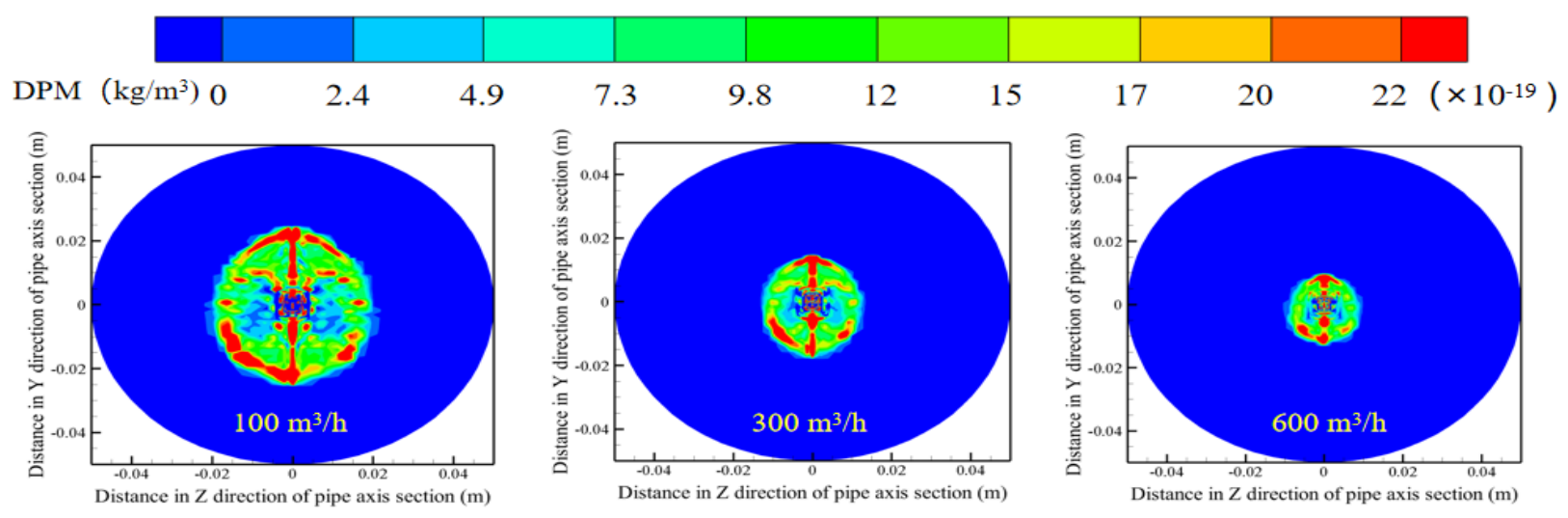

Figure 8. Particle mass concentration distribution at different flow rates.

\subsection{Influence of Pressure Difference on Particle Distribution}

Figure 9 shows the tracer particle distribution at $100 \mathrm{~m}^{3} / \mathrm{h}$ and different pressure differences. Figure 9 shows that at $0.5 \mathrm{MPa}$, the particle distribution area accounts for about $16 \%$ of the cross-sectional area of the pipeline. At $1.0 \mathrm{MPa}$, the particle distribution area accounts for about $21 \%$ of the cross-sectional area of the pipe. At $1.5 \mathrm{MPa}$, the particle distribution area accounts for about $25 \%$ of the pipe cross-sectional area. It can be seen that an increase in the pressure difference can improve the distribution of particles, because when the pressure difference is increased, the velocity of the particles at the outlet of the injection pipe increases, the partial velocity of particles at the outlet along the radial direction increases, and the particles have more momentum in the radial direction, and thus they tend to spread to the wall of the pipe.

Figure 10 shows the curve of the main flow field disturbance range caused by CASE3 under different pressure differences. It can be seen from Figure 10 that, with an increase in the pressure difference, the disturbance intensity at the flow field intersection increases, but the disturbance range does not change significantly. Therefore, increasing the injection pressure difference can improve the particle distribution with fewer side effects, but the pressure resistance of the pipe wall needs to be considered. Hence, increasing the pressure difference cannot fundamentally solve the phenomenon of small particle distribution area. 


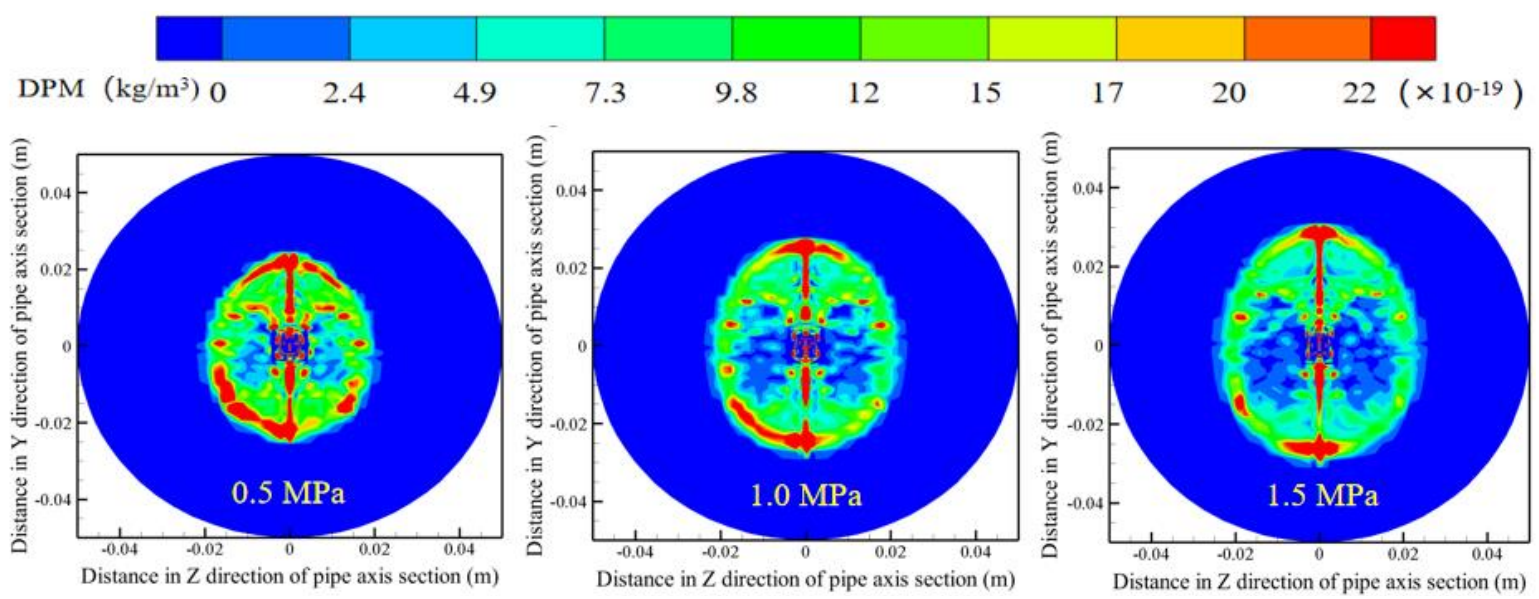

Figure 9. Particle mass concentration distribution at different pressure differences.

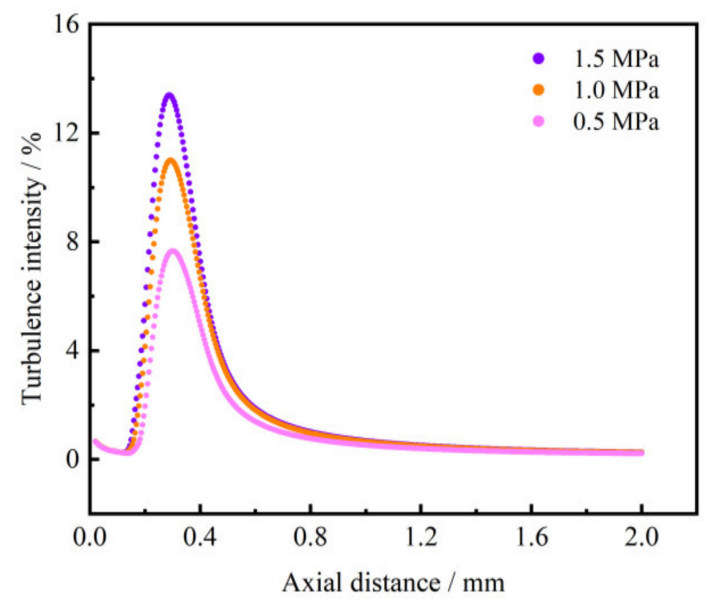

Figure 10. Disturbance range of different pressure difference to main pipeline.

\subsection{L-Shaped Injection Tube Optimization}

The structure of CASE3 is optimized to account for the distribution area of tracer particles is small in CASE3. As the distribution area of tracer particles is small because the radial velocity of the particles is too small, and the horizontal section in CASE3 has the effect of drainage, its length is the key to affect the radial velocity of particles. Therefore, shortening the intersection distance between particles and the main flow field (shortening the horizontal section of CASE3) is the fundamental method to solve the small distribution area of tracer particles in CASE3 under high pressure conditions. In order to explore the relationship between the length of the horizontal section of CASE3 and the distribution of tracer particles, L-shaped tubes with $\mathrm{Lx}=80 \mathrm{~mm}, 50 \mathrm{~mm}$, and $0 \mathrm{~mm}$ were calculated, and the distribution law of tracer particles was obtained as shown in Figure 11. 


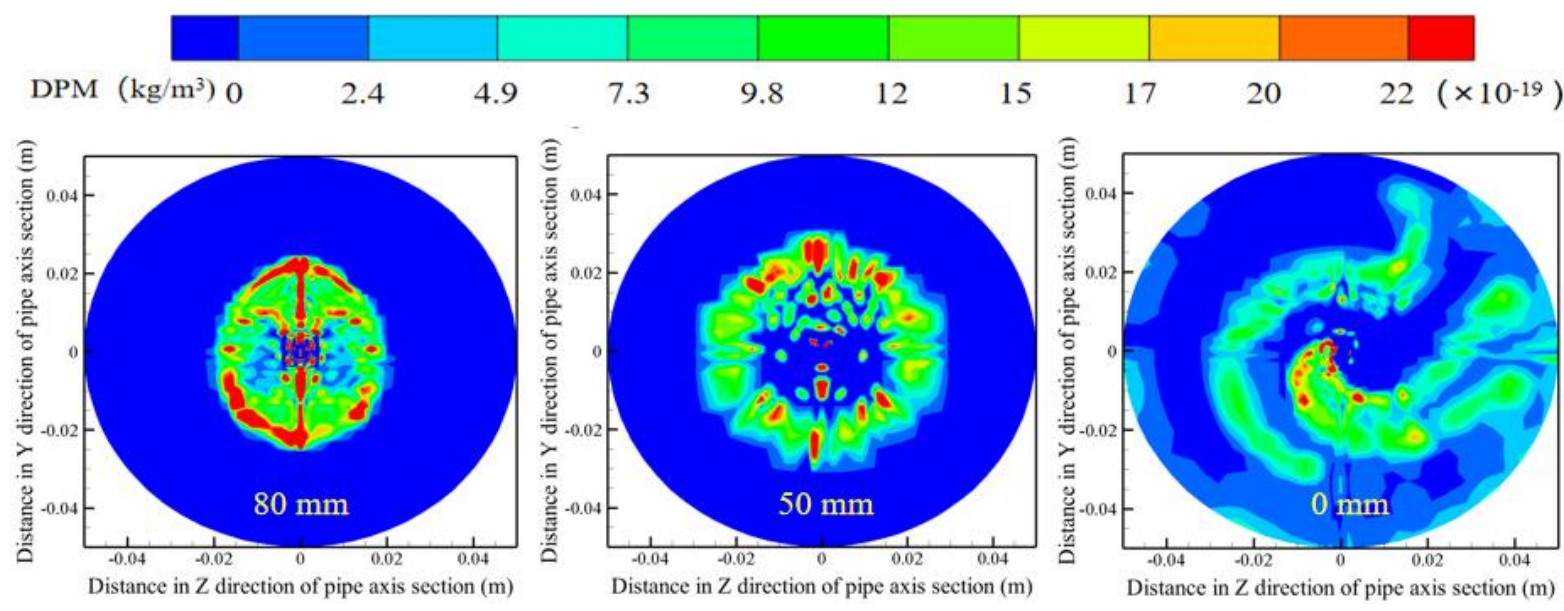

Figure 11. Particle mass concentration distribution with different optimized structures at $0.5 \mathrm{MPa}$.

Figure 11 shows that the horizontal distance of CASE3 plays a decisive role in particle concentration distribution. When $\mathrm{Lx}=50 \mathrm{~mm}$, the particle distribution area increases, accounting for approximately $36 \%$ of the cross-sectional area of the pipeline compared with the original structure, but the particles still cannot fill the pipe. When the horizontal section is removed $(\mathrm{Lx}=0 \mathrm{~mm})$, the tracer particles can reach the area near the pipe wall and fill the entire pipe. In order to understand the disturbance of the optimized CASE3 flow field, the axial turbulence intensity distribution of the main flow field is compared. Figure 12 shows that the axial turbulence intensity distributions with different Lx values are similar. As the intersection distance between the injection flow field and the main flow field decreases after shortening the horizontal section, the peak position of the turbulence intensity is shifted. Moreover, as the surface area of the CASE3 filling pipe into the main pipe decreases, the flow field disturbance caused by the main flow field impinging on the wall of the filling pipe decreases, so the peak turbulence intensity decreases from $13.4 \%$ to $8 \%$. Therefore, the length of the horizontal pipe is set to $0 \mathrm{~mm}$, which is the optimal value.

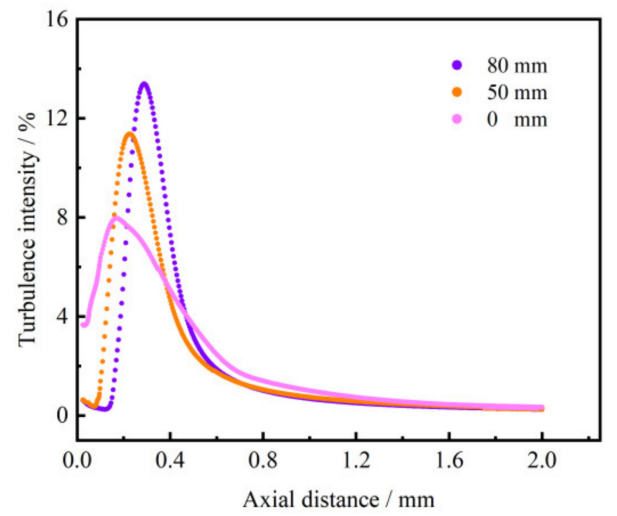

Figure 12. Disturbance of flow field according to length of horizontal section of L-shaped injection tube.

In order to verify the accuracy of numerical calculation, the speed on the axis of the test section is analyzed, as shown in Figure 13, where CV is the numerical calculation result and EV is the PIV measurement result. It can be seen from the figure that there is a certain error between the speed value measured by PIV and the test value calculated numerically. The reason is that the smooth wall is used in the numerical calculation, but there is a loss along the wall in the actual working condition. If the loss along the way caused by wall friction is considered in the calculation, the amount of calculation will increase sharply. Therefore, the pipe wall friction is ignored in the calculation, but the overall trend of the 
calculation results is basically consistent with the measurement results, which can prove the accuracy of the test.

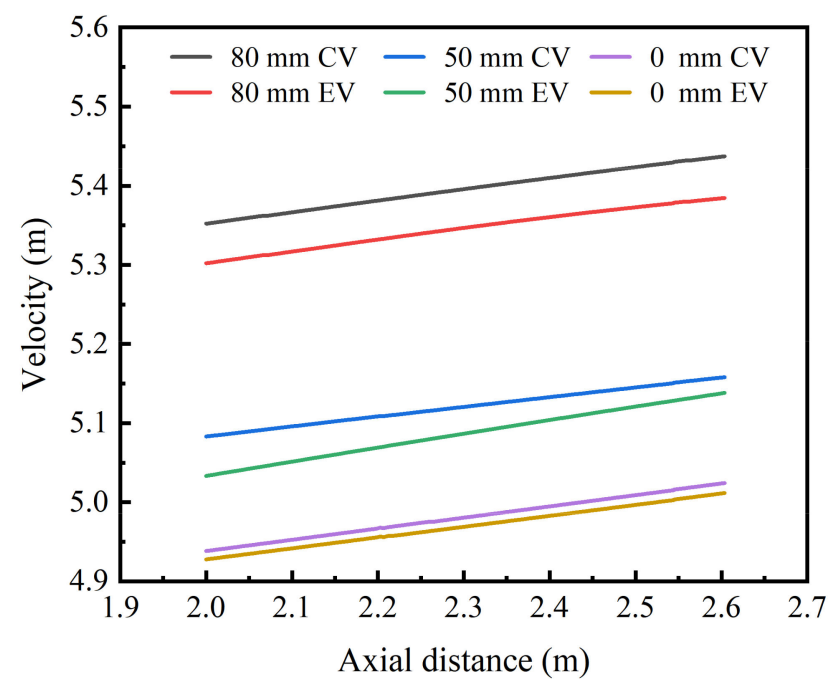

Figure 13. Calculated value is compared with the result value.

\subsection{Experimental Verification Test}

In order to verify that the optimized CASE3 particle distribution can meet the metering requirements of PIV flowmeters, in this study, we performed a test on the optimized CASE3, which was jointly completed by the Chengdu Branch of the National Oil and Gas Large Flow Metering Station and the Key Laboratory of Fluid and Power Machinery of the Ministry of Education of Xihua University. The optimized CASE3 is shown in Figure 14. The horizontal section of CASE3 is eliminated in the optimized structure, and the filling pipe is extended into the main pipe through radial holes in the flange plate; in addition, the flange with the filling device is tightly connected to the main pipe with bolts. Figure 15 shows the field test setup. After the device is connected, the double-cavity double-pulse laser is opened to form a slice light source in the metering section, and the 16-bit crossframe PIV camera is used to collect data in the testing section. Table 1 shows the basic parameters of the PIV devices. Figure 16 shows the comparison between the metering results of a PIV flowmeter with the optimized structure and that of an ultrasonic flowmeter. As shown in Figure 15, the PIV flowmeter used with the optimized CASE3 has a maximum error value of about $2 \%$ between the metering results and the ultrasonic flowmeter at each metering flow rate, and the metering results are good. This result verifies that the optimized structure is applicable to PIV flowmeters.

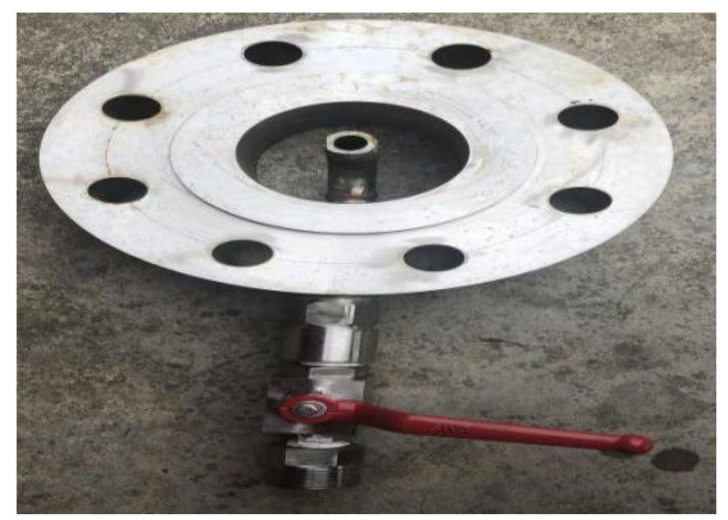

Figure 14. Particle filling section. 


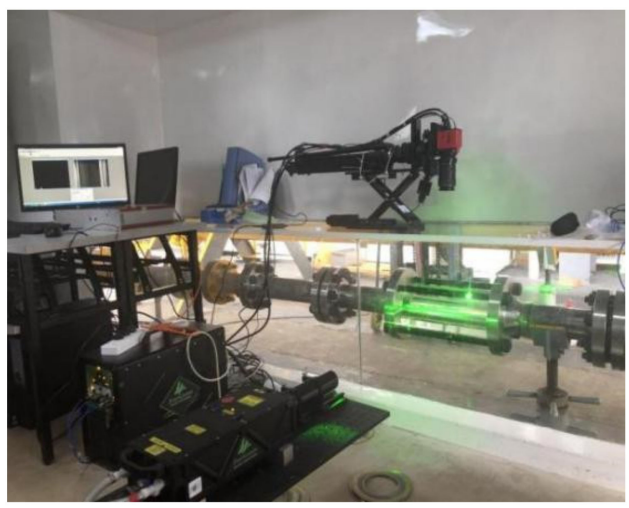

Figure 15. Field test setup.

Table 1. Main technical parameters of PIV system.

\begin{tabular}{cc}
\hline Main Parameters & Technical Indices \\
Function & $\begin{array}{c}\text { Measure the 2D velocity field distribution on a plane } \\
\text { to obtain } \mathrm{U}, \mathrm{V} \text { velocity components, vorticity, velocity } \\
\text { gradients, streamlines, etc. }\end{array}$ \\
Speed measurement range & $0-1000 \mathrm{~m} / \mathrm{s}$ \\
Speed measurement accuracy & $\mathrm{U}, \mathrm{V}$ components $\leq 1 \%$ of reading \\
Measured area & Flow field area $\geq 900 \mathrm{~mm} \times 1000 \mathrm{~mm}$ \\
Overall operating frequency & $15 \mathrm{~Hz}$ \\
Bits & $16 \mathrm{bits}$ \\
\hline
\end{tabular}

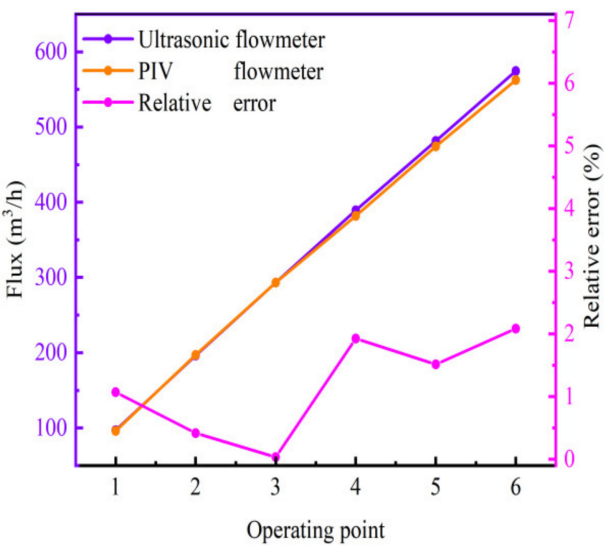

Figure 16. Measurement error.

\section{Discussion}

In this study, the method of adding tracer particles in a PIV flowmeter was investigated by combining numerical calculations and experiments. The disturbance distance of the flow field caused by the confluence of the flow field was compared with that of single pipe injection, multi-pipe injection, and L pipe injection of tracer particles, and the relationship between disturbance distance and flow rate was obtained. At a flow rate of $600 \mathrm{~m}^{3} / \mathrm{h}$, the disturbance distance of single pipe filling, multi-pipe filling, and L pipe filling was 10, 12 and 8 times the pipe diameter, respectively. In comparison, the disturbance distance caused by $\mathrm{L}$ pipe filling was the shortest, hence the $\mathrm{L}$ pipe filling mode was preferred during the test.

However, the relative error between the measurement results of the PIV and ultrasonic flowmeters was larger than $6 \%$ when the $\mathrm{L}$ tube is filled. By observing the test process and data, it was found that the non-uniform distribution of particles was the main cause of the measurement error. 
The relationship between the particle distribution, flow rate, and injection pressure was studied using numerical calculations. It was found that the flow rate is inversely proportional to the particle distribution area, and the injection pressure is positively proportional to the particle distribution area.

However, the desired effect was not achieved by improving the working conditions. To this end, the structure of the L pipe was optimized. By shortening the intersection distance between the injection flow field and the main flow field, the radial velocity of the particles at the outlet of the injection pipe was increased such that the particles were fully mixed with the natural gas in the main flow field, and the measurement requirements of the PIV flowmeter were met. The optimized structure did not increase the disturbance distance of the flow field, and the peak turbulence intensity at the intersection of the flow fields decreased from $13.4 \%$ to $8 \%$.

The optimized structure was used to measure the flow rate of $100 \mathrm{~m}^{3} / \mathrm{h}$ to $600 \mathrm{~m}^{3} / \mathrm{h}$ in six different conditions. In each condition, the maximum relative error of the PIV and ultrasonic flowmeter was about $2 \%$, and the measurement deviation was significantly improved. However, in the natural gas large flow measurement, the manifold structure also has a certain influence on the measurement results of the PIV flowmeter. This study was based on the ideal state of natural gas flow field flow and did not consider the manifold structure on the measurement results; this will be considered in future work.

\section{Conclusions}

A natural gas pipeline is the object of this study, and the method of combining numerical calculations and tests is applied to the PIV flowmeter to compare and analyze the disturbance distance caused by three different particle injection modes: single pipe, multiple pipes and L pipe. It is found that the disturbance distance of the downstream flow field caused by the injection of the L pipe is the smallest, but the particle distribution area is small, which leads to a large relative error between the measurement results of the L-tube and those of the ultrasonic flowmeter. By shortening the intersection distance between the L tube injection flow field and the main flow field, the problem that tracer particles cannot fill the test area is effectively solved. Comparing the measurement results of the optimized PIV flowmeter with those of the ultrasonic flowmeter, the measurement relative error is approximately $2 \%$. The measurement deviation from the ultrasonic flowmeter is significantly improved, which verifies the feasibility of the optimized structure in the PIV flowmeter.

Author Contributions: Conceptualization, Y.Q. and H.C.; methodology, W.L.; software, F.W.; validation, Y.Q., H.C. and W.L.; formal analysis, F.W.; investigation, F.W.; resources, W.L.; data curation, W.L; writing—original draft preparation, Y.Q.; writing—review and editing, Y.Q.; visualization, W.L.; supervision, W.L.; project administration, W.L.; funding acquisition, Z.L. All authors have read and agreed to the published version of the manuscript.

Funding: The Science and Technology Department of Sichuan Province (Grant No.:2020YFH0135). Fluid Machinery and Engineering Key Laboratory of Sichuan Province open fund (szjj2019-023). Thank GUNA RAJ DHAKAL BILAS (Alternative Energy Promotion Center, Nepal) for his help and support in writing this article.

Institutional Review Board Statement: Not applicable.

Informed Consent Statement: Not applicable.

Data Availability Statement: Not applicable.

Conflicts of Interest: The authors declare no conflict of interest. 


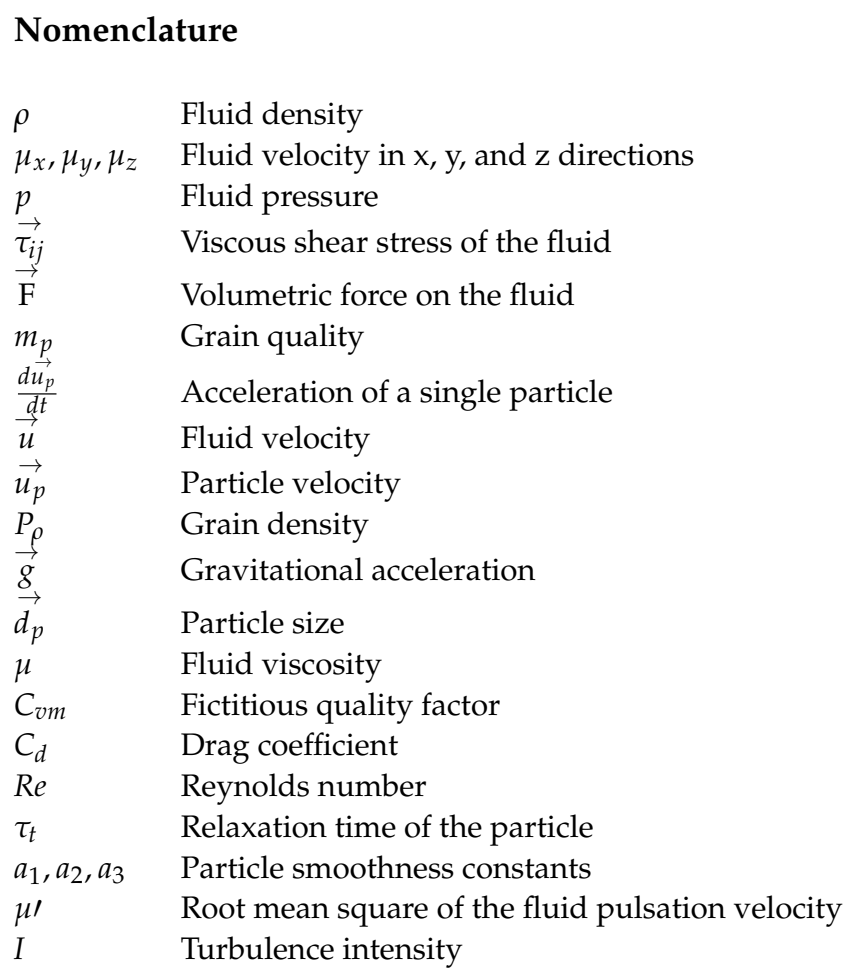

\section{References}

1. U.S. Energy Information Administration. Natural Gas Processing: The Crucial Link between Natural Gas Production and Its Transportation to Market; Office of Oil and Gas: Los Alamos, NM, USA, 2006; pp. 20-22.

2. Economides, M.J.; Wood, D.A. The state of natural gas. J. Nat. Gas Sci. Eng. 2009, 1, 1-13. [CrossRef]

3. Abdullah, N.N.; Anwar, G. An Empirical Analysis of Natural Gas as an Alternative Fuel for Internal Transportation. Int. J. Eng. Lit. Soc. Sci. 2021, 6, 479-485.

4. Meribout, M.; Shehzad, F.; Kharoua, N.; Khezzar, L. An ultrasonic-based multiphase flow composition meter. Measurement 2020, 161, 107806. [CrossRef]

5. Yuchen, S.; Yunqi, S.; Yalan, Q.; Junlian, Y.; Dezhong, W. Experiment and modeling of liquid-phase flow in a venturi tube using stereoscopic PIV. Nucl. Eng. Technol. 2021, 53, 79-92.

6. Antonenkov, D.A. Device for Research of Water Flow Dynamics in Situ Based on the PIV Method. In IOP Conference Series: Earth and Environmental Science; IOP Publishing: Bristol, UK, 2021; Volume 666.

7. Xiaolong, W.; Demin, L.; Xiaobing, L.; Wen, T.; Lianchen, X. Analysis of Internal Flow Field and Pressure Pulsation in Bladeless Region of Pump Turbine. J. Hydroelectr. Eng. 2021, 4, 59-72. Available online: http://kns.cnki.net/kcms/detail/11.2241.TV.2021 0318.1103.008.html (accessed on 4 December 2020).

8. Moneib, H.A.; Mahfouz, A.; El-Fatih, A.; Emara, A. Near-field spray characterization of a spill return atomizer using a PIV laser sheet. Fuel 2021, 289, 119792. [CrossRef]

9. Chae, M.-S.; Chung, B.-J. Investigation of buoyancy influence on mixed convection in a vertical channel through PIV measurement. Int. J. Therm. Sci. 2021, 163, 106776. [CrossRef]

10. Gangfu, L.; Haiwang, L.; Ruquan, Y.; Shuangzhi, X. Experimental Study on Velocity Field and Temperature Field Characteristics of Rotating Boundary Layer. J. Aerosp. Power 2020, 35, 2573-2582.

11. Li, X.; Chen, H.; Chen, B.; Luo, X.; Yang, B.; Zhu, Z. Investigation of flow pattern and hydraulic performance of a centrifugal pump impeller through the PIV method. Renew. Energ. 2020, 162, 561-574. [CrossRef]

12. Sun, C.; Azmi, A.M.; Zhou, T.; Zhu, H.; Zang, Z. Experimental study on wake flow structures of screen cylinders using PIV. Int. J. Heat Fluid Flow 2020, 85, 108643. [CrossRef]

13. Lourenco, L.; Krothapalli, A. On the accuracy of velocity and vorticity measurements with PIV. Exp. Fluids 1995, 18, 421-428. [CrossRef]

14. Yue, Y.; Wang, S.; Bahl, P.; de Silva, C.; Shen, Y. Experimental Investigation of Spout Deflection in a Rectangular Spouted Bed by the PIV Method. Ind. Eng. Chem. Res. 2020, 59, 13810-13819. [CrossRef]

15. Milton-McGurk, L.; Williamson, N.; Armfield, S.W.; Kirkpatrick, M.P. Experimental investigation into turbulent negatively buoyant jets using combined PIV and PLIF measurements. Int. J. Heat Fluid Flow 2020, 82, 108561. [CrossRef]

16. Dellacasagrande, M.; Verdoya, J.; Barsi, D.; Lengani, D.; Simoni, D. Mixed LSE and EPOD based technique for multi-plane PIV measurements synchronization in separated flow condition. Exp. Therm. Fluid Sci. 2021, 122, 110313. [CrossRef] 
17. Versteeg, H.K.; Malalasekera, W. An Introduction to Computational Fluid Dynamics: The Finite Volume Method; Wiley: New York, NY, USA, 1995.

18. Wei, L.; Pei, L.; Chen-Xu, S. Simulation and Prediction of 60.3 mm Elbow Erosion Based on CFD. Surf. Tech. 2020, 49, 178-184. Available online: http:/ / kns.cnki.net/kcms/detail/50.1083.tg.20200507.1636.022.html (accessed on 21 August 2019).

19. Chen, X.; Sreenivasan, K.R. Reynolds number scaling of the peak turbulence intensity in wall flows. J. Fluid Mech. 2020, 908, R3.

20. Gaurier, B.; Carlier, C.; Germain, G.; Pinon, G.; Rivoalen, E. Three tidal turbines in interaction: An experimental study of turbulence intensity effects on wakes and turbine performance. Renew. Energy 2020, 148, 1150-1164. [CrossRef]

21. Arenas-López, J.P.; Badaoui, M. Stochastic modelling of wind speeds based on turbulence intensity. Renew. Energy 2020, 155, 10-22. [CrossRef] 